

\section{DISCLAIMER}

This report was prepared as an account of work sponsored by an agency of the United States Government. Neither the United States Government nor any agency Thereof, nor any of their employees, makes any warranty, express or implied, or assumes any legal liability or responsibility for the accuracy, completeness, or usefulness of any information, apparatus, product, or process disclosed, or represents that its use would not infringe privately owned rights. Reference herein to any specific commercial product, process, or service by trade name, trademark, manufacturer, or otherwise does not necessarily constitute or imply its endorsement, recommendation, or favoring by the United States Government or any agency thereof. The views and opinions of authors expressed herein do not necessarily state or reflect those of the United States Government or any agency thereof. 


\section{DISCLAIMER}

Portions of this document may be illegible in electronic image products. Images are produced from the best available original document. 
Contract No. A.T(29-1)-613 U.S. A. E. C.

This report was prepared as an account of Government sponsored work. Neither the United States, nor the Atomic Energy Commission, nor any person acting on behalf of the Commission:

A. Makes any warranty or representation, expressed or implied, with respect to the accuracy, completeness, or usefulness of the information contained in this report, or that the use of any information, apparatus, method, or process disclosed in this report may not inf ringe privately owned rights; or

B. Assumes any liabilities with respect to the use of, or for damages resulting from the use of any information, apparatus, method, or process disclosed in this report.

As used in the above, "person acting on behalf of the Commission" includes any employee or contractor of the Commission, or employee of such contractor, to the extent that such employee or contractor of the Commission, or employee of such contractor prepares, disseminates, or provides access to, any information pursuant to his employment or contract with the Commis sion, or his employment with such contractor. 


\title{
EFFECT OF MOLECULAR STRUCTURE ON THE THERMAL AGING PROPERTIES OF FLEXIBLE URETHANE FOAMS
}

\begin{abstract}
A series of flexible urethane foams was formulated from diisocyanate terminated polyether prepolymers, using both a polyether diol and an ethylene diaminetetraglycol as extenders. The long term compression set characteristics and the compression deflection properties of these foams were studied. The swelling effect in a solvent, the free isocyanate content, and the role of a carbon black filler on the flexible urethane foam formulation were also evaluated. It was concluded that the total amount of diisocyanate used in the formulation, rather than a variation in the type of isocyanate, has the greatest influence on molecular structure.
\end{abstract}




\section{EFFECT OF MOLECULAR STRUCTURE ON THE \\ THERMAL AGING PROPERTIES OF FLEXIBLE}

URETHANE FOAMS

by

C. H. Smith and S. Lo DeGisi

THE BENDIX CORPORATION

Materials Engineering

Kansas City, Missouri

\section{INT RODU CTION}

Flexible urethane foams possess an extremely complicated molecular arrangement. This is primarily due to the very broad spectrum of avallable starting materials and the countless chemical reactions that may occur during the foam formation. The final polymer contains a great diversity of chemical structures, making available a very wide range of polymer properties. A comprehensive knowledge of the relationship between polymer structure and physical properties is important to fully utilize the engineering capabilities of flexible urethane foams.

Prior work in our laboratory has shown the effect of molecular structure, particularly the diisocyanate, on the load-bearing ability of flexible urethane foams (1). Additional work has now been completed, to extend this type of information into the area of thermal aging.

Previous investigators have studied the thermal stability properties of both polyester and polyether-based urethane polymers $(2)(3)(4)$. They have studied the effects of catalyst, chemical Ilnkages and "secondary bonds" (van der Waal forces) on the aging characteristics of flexible urethane foams $(5)(6)(7)$. The work presented here describes the results of a study to determine the role of the dilsocyanate and polyol. extender, used in flexible urethane foam formulations, has on the heat aging properties of these materials。 
There are several methods that lend themselves to the study of the thermal aging characteristics of flexible urethane foams. For our work, we decided upon a long term compression set test, in combination with a determination of the effect of aging on the compression deflection properties of the foam. Our reasoning for this procedure was that by keeping the foam in a compressed state at an elevated temperature, we would be able to determine not only the stability of the various chemical linkages in the foam, but also the effect of hydrogen bonds present. To further clarify the relationship between polymer structure and aging properties in foams, other methods of investigation were used including: solvent absorption, free isocyanate determination, and the role of a carbon black filler.

All our foams were molded to a desired density using an isocyanate prepolymer-water-extender formulation. Two different types of extenders were used. The isocyanate prepolymers were based on a polyether triol, terminated with secondary hydroxyl groups. Four different commercially available diisocyanates were evaluated in this study.

\section{EXPERIMENTAL PROCEDURE}

\section{A. Physical Testing}

To determine aging characteristics of the urethane formulations, a compression set test in combination with a determination of the effect of aging for 72 and 168 hours on the compression-deflection properties of the foams, were conducted. Two-inch diameter specimens, cut from the cured foam slabs approximately 0.125 inch thick, were used. First a compressiondeflection test, to $50 \%$ of the original thickness, was performed at ambient temperature $(77 \pm 10 \mathrm{~F})$. The specimens were then compressed to $50 \%$ deflected thickness in a compression set fixture as described in ASTM D-395 (10). The compressed specimens were aged at $160 \pm 5 \mathrm{~F}$ for the specified times ( 72 hours and 168 hours). Upon completion of the aging period, the specimens were cooled to ambient temperature while in the compressed state. The specimens were then removed from the compression 
set fixture and allowed to recover for 30 minutes at ambient temperature. The recovered thickness was then measured, using a dial type gage having a stem and foot weight of 25 grams and a foot 1.125 inch in diameter. A compression deflection test, to $50 \%$ of the original thickness, was performed at ambient temperature on the aged specimens. All tests were performed in duplicate and the results averaged.

\section{B. Isocyanate Content}

The free isocyanate content of both filled (carbon black) and unfilled flexible urethane foam samples was determined by the method of Kubitz (8). All the samples were first tested qualitatively and then quantitatively.

The qualitative identification of free isocyanate was accomplished by treating a sample of the material with a test solution containing 0.2 percent of: an n-butylamine-malachite green derivative in a 50:50 mixture of cumene and mineral oil. The presence of a green color is a positive test for as little as 0.005 millimoles of isocyanate. The shade of green is an indication of the amount present, but is not sensitive enough for a quantitative analysis.

The quantitative determination involved the following steps:

1. A weighed foam sample was reacted with an excess of a standard solution of $\mathrm{n}$-butylamine.

2. An aliquot containing unreacted butylamine was withdrawn.

3. A solution of malachite green was added to react with the $\mathrm{n}$-butylamine.

4. The malachite green intensity was measured with a spectrophotometer.

5. The amount of $n$-butylamine that reacted with isocyanate was calculated from a calibration curve [for the decolorization of malachite green by n-butylamine]. 


\section{Solvent Absorption}

The conventional method for absorption measurements on crosslinked polymers consists of immersing weighted or measured specimens into suitable solvents and observing the gain in weight or volume over a period of time. The ideal solvent is one that would cause swelling, but no solution, of the specimen when immersed. For our work with flexible urethane foams, we elected to expose the samples to vapors of pyridine (a known solvent).

Samples of the flexible urethane foam were reduced in particle size to approximately $1-2 \mathrm{~mm}$, and $0.2 \mathrm{gram}$ was weighed into a tared $5 \mathrm{ml}$ beaker. The foam samples were then placed into an 8-inch desiccator which contained $400 \mathrm{ml}$ of pyridine. At various periods of time, the samples were removed from the desiccator, weighed as quickly as possible, and then returned to the desiccator. This weighing operation required approximately 30 seconds for each sample. The percent weight gain was determined after $2,4,6,8,24,26,32$ and 48 hours exposure to the pyridine vapor.

\section{CHEMISTRY AND FOAMS}

\section{A. Prepolymer Preparation}

The molecular structures of the four disocyanates used for this study are given in Figure 1. These structural formulae include the single benzene ring as illustrated by the toluene diisocyanate [TDI] isomers. A fused biphenyl compound is represented by 3,3' dimethyl - 4, 4' diphenyl disocyanate $[$ TODI . Two separated ring diisocyanates, methylene bis (4-phenylisocyanate) $[M D I]$ and methylene bis (3-methyl-4-phenyl isocyanate) $[\mathrm{MMDI}]$ were also evaluated.

The polyether used in the prepolymer preparation was Niax Triol LHT-67, a polyoxypropylene derivative of $1,2,6$ - hexanetriol having an average 
molecular weight of approximately 2500.

The isocyanate prepolymers were prepared by a method similar to that described by Davis, et al, with certain modifications being necessary for the solid diisocyanates (9). The following is a typical prepolymer recipe.

$\begin{array}{ll}\text { Niax Triol LHT }-67 & 1.0 \text { mole } \\ \text { Diisocyanate (1st Part) } & 1.53 \text { moles } \\ \text { Dilsocyanate (2nd Part) } & 2-6 \text { moles }\end{array}$

The "2nd part" isocyanate was varied to adjust the amine equivalent of the finished prepolymerto the desired range of $455 \pm 10$. In the case of prepolymers prepared from a combination of diisocyanates, chain extension was accomplished by the "lst part" while the capping reaction was performed by the " 2 nd part" addition.

Shown in Table I are the diisocyanates and combination of diisocyanates used in prepolymer preparation, along with amine equivalents, formulation number, and viscosities of the finished prepolymers.

Table I. Typical Properties of Prepolymers Made Using Various Diisocyanates

Formulation

Number

254-69

254-80

$254-91$

254-101

$\frac{\text { Diisocyanate }}{65 / 35 \text { TDI }}$

MDI

TODI-65/35 TDI

MMDI-65/35 TDI
Amine

Equivalent

462

461

445

455
Viscosity

$@ 25 \mathrm{C}, \mathrm{cps}$

15,500

14,000

13,100

10,500

B. Foam Formulation.

Two extenders were evaluated in the foam formulations. One was Tetronic 701 (EDTG), a tetrafunctional oxypropylene - oxyethylene derivative of ethylene diamine. This polyether polyol is terminated with primary 
hydroxyl groups and has a molecular weight of approximately 2750 . The other extender used was Pluronic L-61 (PPG), a polyether diol of approximately 2000 molecular weight, having a center block of oxypropylene units, and on each end blocks of oxyethylene units; again the polyether polyol was terminated with primary hydroxyl groups.

Blowing was accomplished through the reaction of water with the free isocyanate groups on the prepolymer to release $\mathrm{CO}_{2}$. A filler, FT carbon black, was added to the formulation at a ratio of approximately $10 \%$ based on total foam weight. A cell stabilizer, DC-199, an alkylsilane - polyoxyalkylene copolymer, was also incorporated into the formulations. A tertiary amine catalyst, N, N, N', N' - tetramethyl - 1, 3 - butanediamine (TMBD) was employed in the foaming formulation. The foaming systems using EPTG as an extender are designated by a - A and those using PPG are coded $-B$. Given below is a typical foaming recipe, based on a prepolymer having an amine equivalent of 450 and using EDTG as an extender.

$\begin{array}{ll}\text { Prepolymer } & 160 \text { parts by weight (PBW) } \\ \text { EDTG } & 48.5 \mathrm{PBW} \\ \text { Distilled Water } & 1.38 \mathrm{PBW} \\ \text { Catalyst (TMBD) } & 0.24 \mathrm{PBW} \\ \text { FT Carbon Black } & 19.4 \mathrm{PBW} \\ \text { DC-119 } & 1.0 \mathrm{PBW}\end{array}$

The foaming mixture was prepared by combining the extender with the carbon black, water, catalyst, and cell stabilizer. These components were blended together and then combined with the prepolymer. The mixer used for this operation was a high speed air-driven stirrer with a 1 -inch tri-blade propeller.

\section{Foam Sample Preparation}

The foamed test slabs prepared for both physical and chemical testing were $6 \times 6 \times 0.125$ inch, with an approximate density of 0.34 grams per cubic centimeter. A mold release agent, Garan 225 (Ram Chemical Co ), was used to facilitate the removal of the cured foam from the aluminum molds. 
The foaming formulation was prepared as described earlier. The liquid mixture was poured into the pre-weighed mold stationed on a laboratory. balance. The balance was set to measure the correct amount of material needed to arrive at the pre-determined density. After the correct quantity of foaming mixture had been transferred into the mold cavity, the mold was removed from the balarice and the top plate fastened in place. Room temperature molds were used for most of the foaming formulations. The molds were allowed to stand for one hour at room temperature (giving the foam time to gel), then the molds were heated for two hours at $225 \pm 5 \mathrm{~F}$ in a forced draft oven. The molds were then removed from the oven and allowed to cool to room temperature. The samples were removed from the molds and given an additional cure of six hours at $225 \pm 5 \mathrm{~F}$.

\section{RESULTS AND DISCUSSION}

Shown in Table $I$ are the results of the compressive aging tests at $165 \mathrm{~F}$ for the various flexible urethane foam formulations. These data indicate that in general the diol (PPG) extended foams had lower compression set and higher load-retention properties than did the tetrafunctional (EDTG) extended formulations. Formulations 254-91A and 254-91B were the only materials tested that displayed an increase in percent load retention upon heat aging at 168 hours. Formulation 254-80B (MDI + PPG) displayed exceptionally low compression set and retained over $50 \%$ of its load bearing capacity.

The results of the qualitative tests for free isocyanate content were positive for both the filled (carbon black) and unfilled flexible urethane foams incorporating the diol (PPG) extender. No tests for free isocyanate content were performed on the EPTG extended formulations, due to their poor showing in the compression aging test. The qualitative test for free isocyanate content is quite sensitive and would show the presence of NCO at a minimum of 0.005 millimole of sample. All foam samples, except formulation 254-80B, showed the same intensity of green color indicating the same level (approximately) of NCO.

Table III gives the results of the quantitative determinations for the free isocyanate content of the flexible urethane foam formulations tested. The 
standard deviation for duplicate, determinations was $\pm 0.023 \%$. It is evident from Table III that the carbon black filler does not affect the free isocyanate content in the foam formulations. The samples containing MDI were much higher in their free NCO content than any of the samples tested.

The percent weight gain due to solvent absorption for the diol extended flexible urethane foam formulations is shown in Table IV. Both filled (carbon black) and unfilled samples were used. Figure 2 shows the difference in solvent absorption between a filled and unfilled foam samples.

When considering the results given in Table IV, the possibility of polymer degradation in the process of dissolution by pyridine cannot be ruled out. Why pyridine appears to be a selective solvent is not fully understood at this time. However, it appeared from our work that if degradation did take place at all, it certainly was not extensive. It was assumed that the urethane polymer must be fairly low in molecular weight in order to obtain solution. The fact that different solution times have been observed, as listed in Table IV for the various formulations, gives rise to evidence of variation in cross-linking.

The data in Table IV shows a definite difference exists between the filled (carbon black) and unfilled urethane foams. The unfilled samples all exhibited a greater solvent absorption than did the carbon black filled materials. As for the basic formulations themselves, the MDI - containing foams did not show as great a gain in weight as did the TDI containing foams.

Figure 2 more clearly shows the difference between the solvent swelling of the filled (carbon black) and unfilled foam samples. The lower solvent absorption of the carbon black filled sample could not be attributed to a greater chemical cross-link density, since the free isocyanate content of the two samples were for all practical purposes identical. This difference was presumably caused by secondary bonding forces between the polymer and the carbon black. Since the different disocyanates used in the foam 
formulations seem to give rise to different degrees of cross-linking (as evidenced from solution times in pyridine) the combination of isocyanate and carbon black would give rise to what might be termed "effective cross-linking".

To further evaluate the role of each component in the diol extended flexible urethane foam formulation, Table $\mathrm{V}$ lists the components for each formulation on a percent by weight basis. All components are of the same approximate concentration except for the MDI. The actual percent of MDI is much higher than for any other of the diisocyanates used.

\section{CONCLUSIONS}

Even though detailed information regarding the chemical structure of flexible urethane foams has not been obtained from this work, several general conclusions can be made. These are listed below:

A. A diol extender appears to produce a more thermally stable flexible urethane foam than does an ethylene diamine tetrafunctional polyol extender.

B. The diisocyanate used in the chain extension reaction for the prepolymer does not affect the molecular structure nearly as much as the "capping off" diisocyanate used in the blowing and cross-linking reactions.

C. The total amount of diisocyanate, rather than the type or reactivity of the diisocyanate, appears to govern the amount of cross-linking in the polymer.

D. Flexible urethane foams seem to have only a few cross-linking sites, which can be attacked by a strong nucleophilic reagent such as pyridine.

E. Flexible urethane foams will dissolve in pyridine and the rate of dissolution is apparently related to the degree of cross-linking.

F. The presence of carbon black filler definitely increases the "effective cross-linking" of the polymers, through secondary bonding forces at the carbon black surface. 
$65 \% 2,4,35 \% 2,6$

Toluene Diisocyanate<smiles>CN(C)C(=O)[O-]</smiles>

$65 \%$<smiles>C[14C](=O)c1cccc([N+](=O)[O-])c1</smiles>

$35 \%$
Methylene bis

(4, Phenyli socyana te)<smiles>O=[N+]([O-])c1ccc(-c2ccc([N+](=O)[O-])cc2)cc1</smiles>

MDI

\section{5/35 TDI}

3, 3' Dimethyl-4, 4'-Biphenyl Diisocyanate

$\mathrm{NCO}$<smiles>Cc1cccc(C(C)C)c1CC(=O)N=O</smiles>

TODI
Methylene bis

(3-Methy1-4-Phenyli socyanate)<smiles>Cc1ccccc1C(=O)N=O</smiles>

MMDI

Figure 1. Chemical Structure of Dilsocyanates Evaluated in Flexible Urethane Foams 


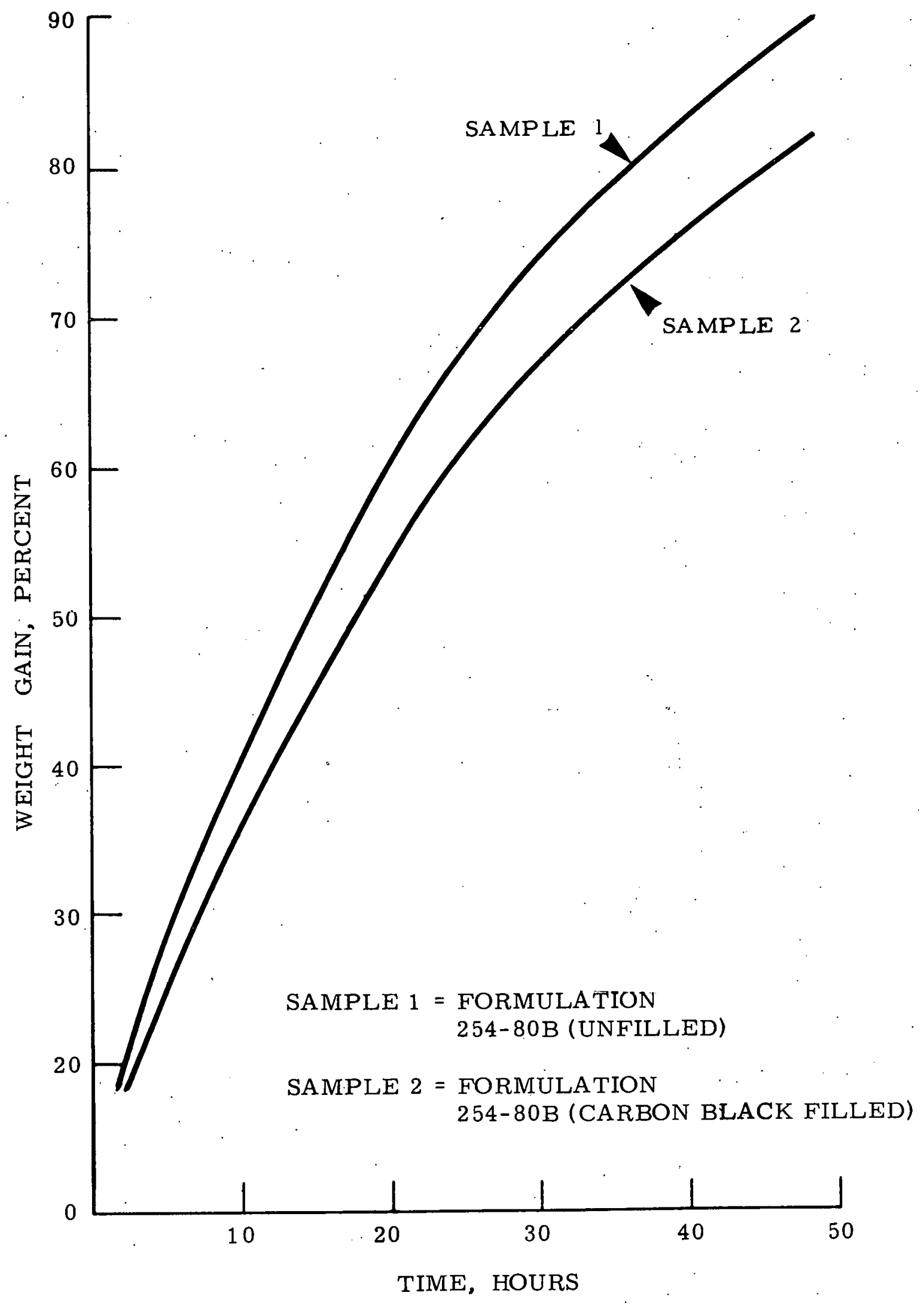

Figure 2. Solvent Absorption for Flexible Urethane Foams 
Table II. Compressive Aging Properties of Flexible Urethane Foam at $165 \mathbf{F}$

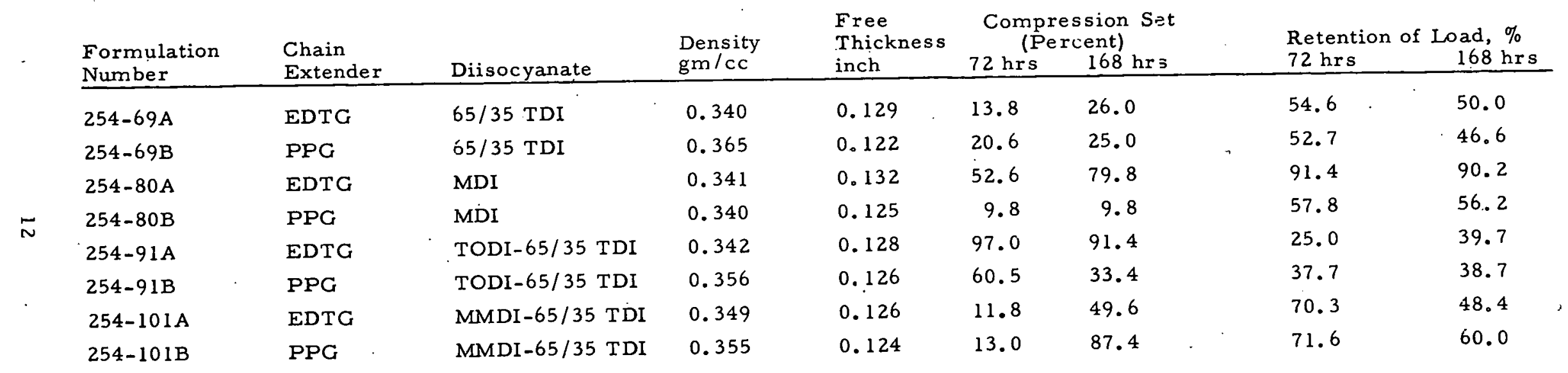


Table III. Free Isocyanate Content of Diol Extended Flexible Urethane Foams

NCO Content, \%

$\begin{aligned} & \text { Formulation } \\ & \text { Number }\end{aligned}$
$254-69 B(1)$
$254-69 B(2)$
$254-80 B(1)$
$254-80 B(2)$
$254-91 B(1)$
$254-91 B(2)$
$254-101 B(1)$
$254-101 B(2)$

Diisocyanate
$65 / 35 \mathrm{TDI}$
$65 / 35 \mathrm{TDI}$
MDI
MDI
TODI-65/35 TDI
TODI-65/35TDI
MMDI-65/35TDI
MMDI-65/35TDI

Duplicates

$0.000 \quad 0.034$

0.0570 .036

0.1390 .144

0.1280 .109

- 0.031

0.0550 .070

$0.046 \quad 0.024$

$0.050-0.033$
Average

0.02

D. 05

D. 14

0.12

0.03

0.07

0.04

0.04

1. Unfilled Sample

2. Filled (Carbon Black Sample) 
Table IV. Solvent Absorption in Pyridine for Diol Extended Urethane Foams

Weight Gain, \%

Exposure Time

\begin{tabular}{llccccccccc}
$\begin{array}{l}\text { Formulation } \\
\text { Number }\end{array}$ & Diisocyanate & & $\underline{2}$ & $\underline{4}$ & $\underline{6}$ & $\underline{8}$ & $\underline{24}$ & $\underline{26}$ & $\underline{32}$ & $\underline{48}$ \\
\cline { 2 - 11 } $254-69 \mathrm{~B}(1)$ & 65/35TDI & & 17.6 & 24.5 & 30.4 & 34.6 & 70.7 & 70.2 & 74.1 & 91.3 \\
254-69B(2) & $65 / 35 \mathrm{TDI}$ & & 16.9 & 24.7 & 28.9 & 33.0 & 66.0 & 65.2 & 69.0 & 85.5 \\
$254-80 \mathrm{~B}(1)$ & MDI & 17.9 & 25.0 & 30.4 & 34.6 & 68.6 & 68.2 & 72.5 & 90.4 \\
$254-80 \mathrm{~B}(2)$ & MDI & 17.3 & 23.2 & 27.6 & 31.5 & 62.9 & 61.9 & 65.8 & 82.4 \\
$254-91 \mathrm{~B}(1)$ & TODI-65/35TDI & 18.2 & 25.4 & 31.1 & 35.6 & 69.7 & 69.3 & 73.5 & 91.4 \\
$254-91 \mathrm{~B}(2)$ & TODI-65/35TDI & 16.6 & 23.4 & 28.6 & 32.6 & 63.8 & 63.6 & 67.2 & 83.2 \\
$254-101 \mathrm{~B}(1)$ & MMDI-65/35TDI & 17.6 & 24.7 & 30.6 & 35.2 & 69.6 & 69.4 & 73.8 & 91.9 \\
$254-101 \mathrm{~B}(2)$ & MMDI-65/35TDI & 16.6 & 23.5 & 28.9 & 33.2 & 64.8 & 64.0 & 67.4 & 83.1
\end{tabular}

1. Unfilled Samples

2. Filled (Carbon Black Samples) 
Table V. Formulations for Diol Extended Flexible Urethane Foams

Formulation Number

$$
\text { (All values are \% by weight) }
$$

\begin{tabular}{ll} 
Material & \multicolumn{1}{c}{ Vendor } \\
LHT-67 & Union Carbide \\
L-61 & Wyandotte \\
TDI & Mobay \\
MDI & Mobay \\
MMDI & Carwin \\
TODI & Carwin \\
H2 $\odot$ & - \\
TMBD & Union Carbide \\
DC-199 & Dow Corning \\
Benzoyl Chloride & Fisher \\
Carbon Black & Vanderbilt
\end{tabular}

\begin{tabular}{|c|c|}
\hline 254-69B & $254-80 \mathrm{~B}$ \\
\hline 40.47 & 35.77 \\
\hline 42.88 & 41.36 \\
\hline 15.19 & \\
\hline & 21.63 \\
\hline 0.76 & 0.78 \\
\hline 0.11 & 0.14 \\
\hline 0.56 & 0.29 \\
\hline 0.03 & 0.03 \\
\hline 9.89 & 9.89 \\
\hline
\end{tabular}

254-91-B

36.59

45. 31

10.42

0.78

14

0.03

9.89

6.26

0.73

0.13

0.53

0.03

9. 85
254-101B

37.38

43.81

10.64

6.71
0.75

0.13

0.55

0.03

9.87 


\section{LITERATURE CITED}

1. Smith, C. H., et al, SPE Journal, 8, No. 4, 455 (1962).

2. Engel, R. E., et al, J App. Polymer Sci , 7, 1679 (1963).

3. Bolin, R. E., et al, J Chem and Eng Data., 4, 261 (1959).

4. Sandridge, R. L., et al, J Chem and Eng Data, 5, 495 (1960).

5. Winkler, J., Rubber Age, 81, No. 5, 799 (1957).

6. Saunders, J. H., Rubber Chem \& Technol , 32, 337 (1959).

7. Saunders, J. H., Rubber Chem \& Technol, 33, $1259(1960)$.

8. Kabitz, K. A., Anal. Chem, 29, 814 (1957).

9. Davis, S., et al, Isocyanate Symposium, Society of Plastics

Engineers, Minneapolis, Oct., 1957.

10. Am Soc Testing Materials, Philadelphia, Pa., ASTM D-395.

\section{ACKNOWLEDGMENTS}

The authors wish to express their appreciation to Edwin Slagel for preparation of both the isocyanate prepolymers and the foamed test specimens, to Department 213 for the physical and chemical testing, and to The Bendix Corporation. 